Original article

\title{
Diagnostic accuracy and pitfalls of fine needle aspiration cytology and scrape cytology in oral cavity lesions
}

\author{
Nesreen H. Hafez, Mohamed I. Fahim \\ National Cancer Institute, Cairo University, Giza, Egypt
}

Received 03 August 2014, Accepted 19 September 2014

(C) 2014, Hafez N.H., Fahim M.I.

(C) 2014, Russian Open Medical Journal

Abstract: Background - The oral cavity can be home for a wide variety of lesions. To date, biopsy has remained the gold standard for diagnosing these lesions. Purpose - This study was carried out to assess the diagnostic accuracy of cytology in the oral lesions and to address the cytologic-histologic correlation.

Patients and Methods - This prospective study included 72 patients with intraoral lesions. Fine needle aspiration cytology (FNAC) or scrap cytology was performed. The smears were immediately fixed in $95 \%$ alcohol for Papanicolaou staining. If there was sufficient material, cell block was prepared. When indicated immunocytochemical study was ordered. Final cytologic results were then compared with the definitive histopathological diagnoses which were considered the gold standard.

Results - Cytologically, 28 patients (38.9\%) were diagnosed as benign/atypical and $44(61.1 \%)$ as malignant/suspicious. The most common benign cytologic diagnosis was inflammation ( $42.9 \%$ of benign cases). The most common malignant cytologic diagnosis was squamous cell carcinoma (36.4\%). Cytologic diagnoses were compared with histopathologic ones. There were 3 false negative cases and one false positive case. The sensitivity was 93.5\%; specificity was 96.2\%; positive predictive value (PPV) was 97.7\%; negative predictive value (NPV) was $89.3 \%$ with a diagnostic accuracy of $94.4 \%$. P-value was $<0.001$. Kappa was 0.882 .

Conclusion - FNAC was found to be highly accurate in the diagnosis of oral lesions. Detailed cytomorphologic examination coupled with clinical data and appropriate immunocytochemical study, in some cases, can lead to an accurate diagnosis. Overlapping features of some tumors, especially in minor salivary gland, as well as limitation of sampling, were responsible for the inaccurate diagnoses.

Keywords: cytology, oral cavity, histopathology correlation

Cite as Hafez NH, Fahim MI. Diagnostic accuracy and pitfalls of fine needle aspiration cytology and scrape cytology in oral cavity lesions. Russian Open Medical Journal 2014; 3: 0405.

Correspondence to Dr Nesreen Hassan Hafez. E-mail: nesreennci@hotmail.com. Tel.: 0222607376-01004959148.

\section{Introduction}

Swellings of oral and oropharyngeal area are a frequent complaint of patients seeking the services of head and neck surgery. The nature of these swellings varies widely, so there is a need to establish an accurate diagnosis and to define the appropriate conduct of procedures. To date, punch biopsy or open surgical biopsy has remained the gold standard for obtaining tissue for the diagnosis of suspicious lesions of the oral cavity, oropharynx, and nasopharynx [1]. Biopsy is expensive, invasive, more painful technique and producing unwanted bleeding as oral mucosa is very vascular. Biopsy needs more time for its processing and reporting leading to delay in the planning of definitive treatment [2]. It also presents limitations when the lesions are large and in these cases it is important to select the most appropriate site of biopsy. Moreover many times a surgeon does not like an encapsulated tumor to be interrupted. It may not be possible to carry out biopsy in every case as some of the patients may be medically compromised and a few patients with asymptomatic lesion may not give their consent for biopsy [3]. Exfoliative (sputum) cytology has been attempted, but this method has high false negative rates up to $37 \%$. It was most useful for superficial epithelial lesions but not for subepithelial lesions [4].

Fine needle aspiration cytology (FNAC) has gained popularity as a rapid, safe, cost-effective, minimally invasive, outpatient and accurate procedure that requires little equipment to diagnose masses in various organs including the head and neck region. If necessary, a reaspiration can be done quickly at the time of initial testing in cases of inadequate material. FNAC helps in avoiding surgical procedure in condition like non-neoplastic or inflammatory lesions and in metastatic tumors [5]. The most commonly described advantages of the oral FNAC are follow-up of previously diagnosed cases and preoperative diagnoses of lesions, allowing the surgeon and the patient to discuss and plan better for further course of action [6]. Scrape cytology has a wide clinical application in assessment of oral and oropharyngeal mucosal abnormalities, which include leukoplakia, erythroplakia and ulcers. Early diagnosis of dysplasia, preinvasive or early invasive tumors is essential for permitting high cure rate. In contrast to sputum cytology, scrape cytology allow sampling of all epithelial layers including the basal cells [7].

However the use of cytopathology in the diagnosis of oral and oropharyngeal lesions is not being commonly practiced. Only a few 
previous studies addressed its accuracy [3,5]. Diversity of lesions, difficulties in reaching and aspirating them and the difficulty involved in fixing the lesion, make the cytological diagnosis of oral/oropharyngeal lesions difficult [8].

The aim of this study was planned to assess the efficacy of cytological procedure to accurately diagnose intraoral lesions and to address the cytologic-histologic correlation, with emphasis on diagnostically difficult cases in order to avoid diagnostic pitfalls.

\section{Material and Methods}

This prospective study included 72 patients presented with definitive oral masses, leukoplakia or ulcers. The cases were referred from Surgical Oncology department to Cytology unit, Pathology department, National Cancer Institute, Cairo University, in the period from September 2010 to May 2013.

The data regarding age, sex, site, nature of the lesions and any associated local or systemic symptoms were recorded from the patients at the time of the procedure and from their files.

The frosted end of the slides was labeled with the patient's first name and the cytology number in pencil. For oral mases, FNAC was carried out by intraoral or extraoral approach in sitting position with head support using 23-gauge disposable needle attached to a 5-ml plastic syringe without local anesthesia. In some cases, assistant doctor used a tongue depressor to enable better visualization of the lesion. After trying to fix the mass, the needle was inserted into the lesion or into the indurated edge of the ulcer followed by aspiration from different portions of the mass by altering the direction of the needle inside the mass while a steady suction was applied to the piston and by giving two passes. The cytological materials were immediately spread on the glass slides. At least two smears were prepared from each lesion. For leukoplakia, the center of the lesion was chosen for firm scrapping and for ulcers without indurated base or edge, the superficial necrotic surface was removed from the ulcers prior to scraping; firm scraping was done with the edge of tongue depressor. Quick spreading of the collected material on the glass slides was performed. On-site immediate evaluation for the adequacy of all smears was carried out using May-Grünwald Geimsa (MGG) stain on one slide. The remained slides were immediately fixed in $95 \%$ ethyl alcohol. When the smear was regarded as unsatisfactory, after immediate microscopic examination, the procedure was repeated whenever possible.

Inadequate smears, that we could not re-aspirate them again due to the tiny size, were excluded from the study. Patients who had not returned back for further histopathological examination or refusing cytology/biopsy were also excluded. All patients gave their consents to participate to this study.

The puncture or scraping sites were covered with gauze and firm pressure was applied to stop bleeding and prevent hematoma formation. No major complications were reported but only prolonged bleeding was observed in few cases. Firm compression for more time was needed after the procedure. Gag reflex or vomiting were also reported in some cases.

The smears were left in alcohol for 30 minutes at room temperature then stained using modified Papanicolaou stains. If there was sufficient material in the needle, a cell block was prepared by fixing the material in $10 \%$ neutral-buffered formalin. The cell block material was embedded in paraffin; thin section was cut and stained by hematoxylin-eosin stain for evaluation of adequacy of the cell block and mini-tissue architecture.
The slides of all cases were examined microscopically to reach a definitive diagnosis. When cytomorphology was inconclusive, immunocytochemical (ICC) study was ordered after a provisional diagnosis in an effort to classify the lesion or to define the malignant cell type (epithelial, mesenchymal, or lymphoid). In cases with available cell block, additional $5-\mu \mathrm{m}$ paraffin sections were prepared on positively charged glass slides for the ICC staining. A panel of monoclonal antibodies was used whenever needed.

At the time of final cytological diagnosis, the modified Papanicolaou-stained smears, hematoxylin and eosin-stained sections of the available cell block and the immunocytochemically stained slides were evaluated. The final cytological aspirates were categorized into: a) benign; b) atypical squamous cells of undetermined significance in which cells displayed increase N/C ratio but with regular nuclear contour and evenly distributed chromatin pattern (abnormalities more marked than simple reactive changes but do not display a squamous intraepithelial lesion); c) suspicious for malignancy; d) malignant.

Subsequent histologic tissue diagnoses of either punch biopsy or excised specimen were available for all cases. Cytological and histopathological diagnoses were correlated. The definitive histopathologic report was the gold standard diagnosis against which FNAC was compared. Cases with cytohistological disparity were selected and re-evaluated for the detection of possible cause. For statistical analysis, benign and atypical squamous cells diagnoses were considered negative and malignant and suspicious cases were considered positive. Diagnostic accuracy, sensitivity, specificity, positive predictive value, negative predictive value and $p$-value were calculated. Kappa value was further applied to compare the agreement between the FNAC diagnosis and biopsy diagnosis.

\section{Results}

Among the 72 patients included in the study, there were 45 male and 27 female patients. The male to female ratio was 1.7:1. Age of the patients ranged from 16 to 71 years with a mean age of 43.9. The maximum number of patients was in the age group 40 59 years ( 32 patients) (Table 1 ).

The most commonly involved site was the palate comprising $21 / 72$ cases $(29.2 \%)$, followed by tongue 19 cases $(26.4 \%)$, buccal mucosa and floor of mouth 8 cases each (11.1\%), lip mucosa 5 cases (6.9\%), retromolar region and tonsillar area 4 cases each (5.6\%), gingival mucosa 3 cases (4.2\%) (Table 1). Palate was the most common site for benign lesions ( 8 cases) while palate and tongue were the most common sites for malignant lesions (13 cases for each).

As regard the nature of the lesions, 46 patients $(63.9 \%)$ had definitive oral masses, 20 patients $(27.8 \%)$ had ulcerative lesions and 6 patients (8.3\%) had white patches (leukoplakia) (Table 1).

\section{FNAC final results}

Cytologically, 28 patients (38.9\%) were diagnosed as benign/atypical and $44(61.1 \%)$ as malignant/suspicious. The most common benign cytologic diagnosis was inflammation (acute abscess or chronic inflammation) in 12 cases (42.9\%) followed by pleomorphic adenoma in 8 cases (28.6\%) (Figure 1), atypical squamous cells of undetermined significance in 4 cases $(14.3 \%)$. other benign lesions included; reactive lymphoid hyperplasia, myoepithelial tumor (Figure 2), granular cell tumor (Figure 3) and epidermoid inclusion cyst in one case for each (Table 2). 
Table 1. Clinical characteristics of the 72 studied cases diagnosed by cytology

\begin{tabular}{|c|c|c|c|c|}
\hline Final cytodiagnosis (no.) & Site of involvement (no.) & Age range & $M: F$ & Nature of lesion (no.) \\
\hline \multicolumn{5}{|l|}{ Benign / Atypical (28) } \\
\hline Inflammation & $\begin{array}{l}\text { - Tongue (4) } \\
\text { - Palate (3) } \\
\text { - Retromolar trigone (2) } \\
\text { - Buccal mucosa (2) } \\
\text { - Lip mucosa (1) }\end{array}$ & $19-68$ & $2: 1$ & $\begin{array}{l}\text { - mass (8) } \\
\text { - ulcer (4) }\end{array}$ \\
\hline Atypical squamous cells & $\begin{array}{l}\text { - Retromolar trigone (2) } \\
\text { - Tongue (1) } \\
\text { - Gingival mucosa (1) }\end{array}$ & $35-44$ & $1: 1$ & $\begin{array}{l}\text { - ulcer (2) } \\
\text { - leukoplakia (2) }\end{array}$ \\
\hline Pleomorphic adenoma & $\begin{array}{l}\text { - Floor of mouth (5) } \\
\text { - Palate (3) }\end{array}$ & $39-52$ & $1.7: 1$ & - mass (8) \\
\hline Reactive lymphoid hyperplasia & - Tonsillar area (1) & $21-29$ & $1: 0$ & - mass (1) \\
\hline Myoepithelial tumor & - Palate (1) & 45 & 1:0 & - mass (1) \\
\hline Granular cell tumor & - Tongue (1) & 49 & $1: 0$ & - mass (1) \\
\hline Epidermoid inclusion cyst & - Palate (1) & 32 & 1:0 & - mass (1) \\
\hline \multicolumn{5}{|l|}{ Malignant / Suspicious (44) } \\
\hline Squamous cell carcinoma & $\begin{array}{l}\text { - Tongue (7) } \\
\text { - Palate (3) } \\
\text { - Buccal mucosa (3) } \\
\text { - Gingival mucosa (2) } \\
\text { - Lip mucosa (1) }\end{array}$ & $41-71$ & $4.3: 1$ & $\begin{array}{l}\text { - ulcer (8) } \\
\text { - mass (5) } \\
\text { - leukoplakia (3) }\end{array}$ \\
\hline Suspicious squamous cells & $\begin{array}{l}\text { - Tongue (3) } \\
\text { - Palate (3) } \\
\text { - Lip mucosa (1) }\end{array}$ & $43-51$ & $2.5: 1$ & $\begin{array}{l}\text { - ulcer (6) } \\
\text { - leukoplakia (1) }\end{array}$ \\
\hline Undifferentiated carcinoma & $\begin{array}{l}\text { - Tongue (3) } \\
\text { - Buccal mucosa (2) } \\
\text { - Lip mucosal (1) }\end{array}$ & $38-51$ & $1: 2$ & - mass (6) \\
\hline Mucoepidermoid carcinoma & - Palate (5) & $43-66$ & $1.5: 1$ & - mass (5) \\
\hline Lymphoma & $\begin{array}{l}\text { - Tonsillar area (3) } \\
\text { - Palate (1) }\end{array}$ & $16-67$ & $1: 1$ & - mass (4) \\
\hline Adenoid cystic carcinoma & - Floor of mouth (3) & $46-70$ & $1: 2$ & - mass (3) \\
\hline Basal cell adenocarcinoma & $\begin{array}{l}\text { - Buccal mucosa (1) } \\
\text { - Lip mucosa (1) }\end{array}$ & 55 & $0: 2$ & - mass (2) \\
\hline Malignant melanoma & - Palate (1) & 49 & $0: 1$ & - mass (1) \\
\hline
\end{tabular}

Table 2. Comparison between cytological diagnoses and their respective histopathological diagnoses

\begin{tabular}{|c|c|c|c|c|}
\hline Final cytological diagnoses & no. & Histopathological diagnoses & no. & Remark \\
\hline Benign / Atypical & 28 & & & \\
\hline Inflammation & 12 & $\begin{array}{l}\text { - Inflammation } \\
\text { - Giant cell reparative granuloma } \\
\text { - Squamous cell carcinomma }\end{array}$ & $\begin{array}{l}9 \\
2 \\
1\end{array}$ & $\begin{array}{l}\text { TN } \\
\text { TN } \\
\text { FN }\end{array}$ \\
\hline Atypical squamous cells & 4 & $\begin{array}{l}\text { - Hyperplastic squamous cells } \\
\text { - Hyperplastic cells é moderate dysplasia }\end{array}$ & $\begin{array}{l}2 \\
2\end{array}$ & $\begin{array}{l}\text { TN } \\
\text { TN }\end{array}$ \\
\hline Pleomorphic adenoma & 8 & $\begin{array}{l}\text { - Pleomorphic adenoma } \\
\text { - Polymorphous low grade adenocarcinoma (PLGA) }\end{array}$ & $\begin{array}{l}7 \\
1 \\
\end{array}$ & $\begin{array}{l}\text { TN } \\
\text { FN }\end{array}$ \\
\hline Reactive lymphoid hyperplasia & 1 & - Follicular lymphoma & 1 & FN \\
\hline Myoepithelial tumor & 1 & - Pleomorphic adenoma (PA) prominent myoepithelial cells & 1 & TN \\
\hline Granular cell tumor & 1 & - Granular cell tumor & 1 & TN \\
\hline Epidermoid inclusion cyst & 1 & - Benign squamous cyst & 1 & TN \\
\hline Malignant / Suspicious & 44 & & & \\
\hline Squamous cell carcinoma & 16 & - Squamous cell carcinoma & 16 & TP \\
\hline Suspicious squamous cells & 7 & $\begin{array}{l}\text { - Squamous cell carcinoma } \\
\text { - Chronic active inflammation }\end{array}$ & $\begin{array}{l}6 \\
1\end{array}$ & $\begin{array}{l}\text { TP } \\
\text { FP }\end{array}$ \\
\hline Undifferentiated carcinoma & 6 & $\begin{array}{l}\text { - Mucoepidermoid carcinoma } \\
\text { - Unclassified carcinoma }\end{array}$ & $\begin{array}{l}4 \\
2 \\
\end{array}$ & $\begin{array}{l}\text { TP } \\
\text { TP }\end{array}$ \\
\hline Mucoepidermoid carcinoma & 5 & $\begin{array}{l}\text { - Mucoepidermoid carcinoma } \\
\text { - Adenocarcinoma }\end{array}$ & $\begin{array}{l}4 \\
1\end{array}$ & $\begin{array}{l}\mathrm{TP} \\
\mathrm{TP}\end{array}$ \\
\hline B cell NHL & 4 & $\begin{array}{l}\text { - Mucosa associated lymphoid tissue lymphoma (MALT) } \\
\text { - Diffuse large B cell lymphoma (DLBCL) }\end{array}$ & $\begin{array}{l}1 \\
3 \\
\end{array}$ & $\begin{array}{l}\text { TP } \\
\text { TP }\end{array}$ \\
\hline Adenoid cystic carcinoma & 3 & $\begin{array}{l}\text { - Adenoid cystic carcinoma } \\
\text { - Polymorphous low grade adenocarcinoma (PLGA) }\end{array}$ & $\begin{array}{l}2 \\
1 \\
\end{array}$ & $\begin{array}{l}\text { TP } \\
\text { TP }\end{array}$ \\
\hline Basal cell adenocarcinoma & 2 & $\begin{array}{l}\text { - Basal cell adenocarcinoma } \\
\text { - Basosquamous adenocarcinoma }\end{array}$ & $\begin{array}{l}1 \\
1 \\
\end{array}$ & $\begin{array}{l}\text { TP } \\
\text { TP }\end{array}$ \\
\hline Malignant melanoma & 1 & - Malignant melanoma & 1 & TP \\
\hline
\end{tabular}

TP, true positive cases; FN, false negative cases; FP, false positive cases; TN, true negative cases. 


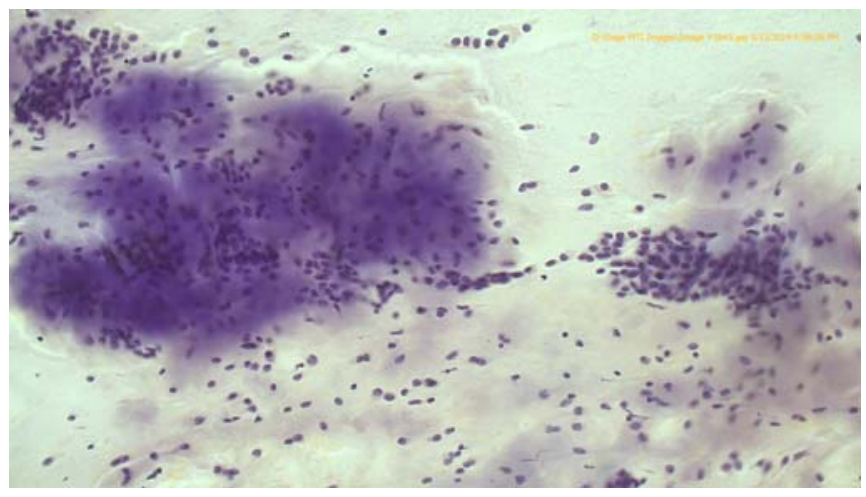

Figure 1. A fine needle aspiration (FNA) smear revealed chondromyxoid stroma admixed with epithelial and separate myoepithelial cells. Histologic follow up confirmed the cytologic diagnosis of pleomorphic adenoma (Papanicolaou stain x200).

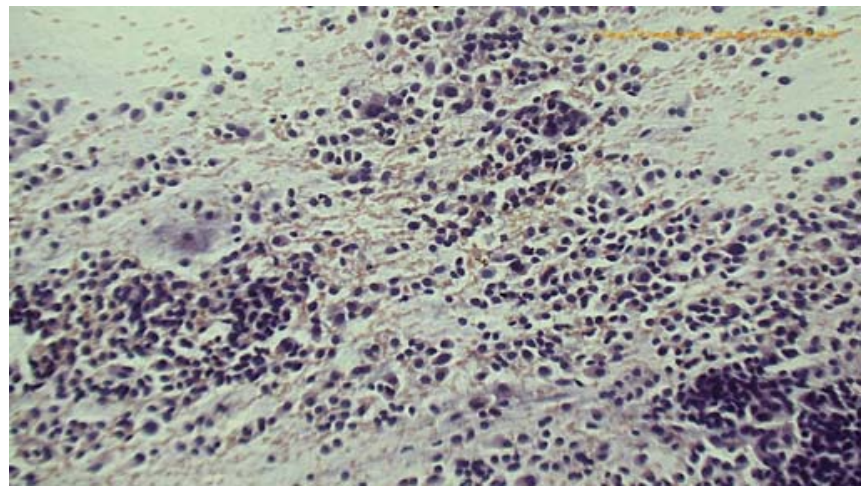

Figure 2. A FNA smear showed cell rich aspirate of loosely cohesive plasmacytoid cells with sparse mucoid substance in the background. Misdiagnosed cytologically as myoepithelioma and proved histopathologically as pleomorphic adenoma with predominant myoepithelial component (Papanicolaou stain $\times 200$ ).

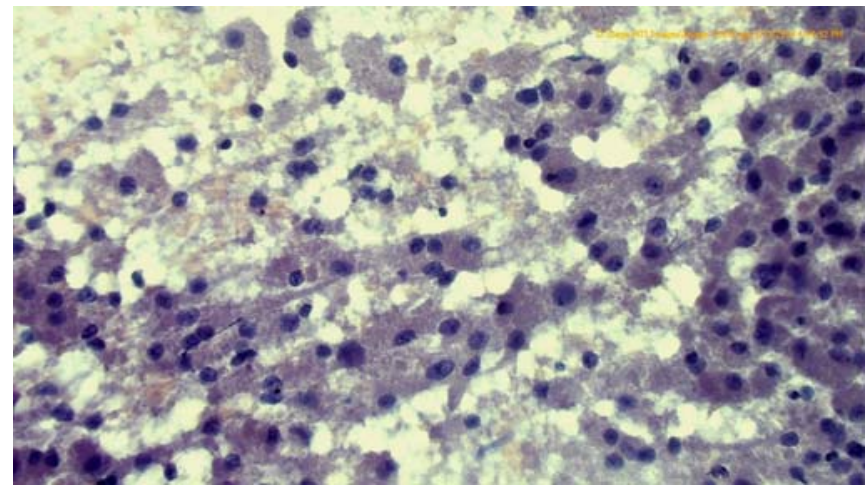

Figure 3. A FNA smear of granular cell tumor displayed discohesive clusters of uniform large cell with abundant granular cytoplasm and indistinct cell border. Corresponding histologic section demonstrated granular cells tumors (Papanicolaou stain x400).

On the other hand, the most common malignant cytologic diagnosis was squamous cell carcinoma in 16 cases (36.4\%) followed by suspicious squamous cells in 7 cases (15.9\%), undifferentiated carcinoma in 6 cases (13.6\%), mucoepidermoid carcinoma in 5 cases each $(11.4 \%)$, suspicious for lymphoma in 4 cases $(9.1 \%)$, adenoid cystic carcinoma (Figure 4) in 3 cases $(6.8 \%)$, basal cell adenocarcinoma in 2 cases (4.5\%) (Figure 5) and suspicious for malignant melanoma in one case (2.3\%) (Figure 6) (Table 2).

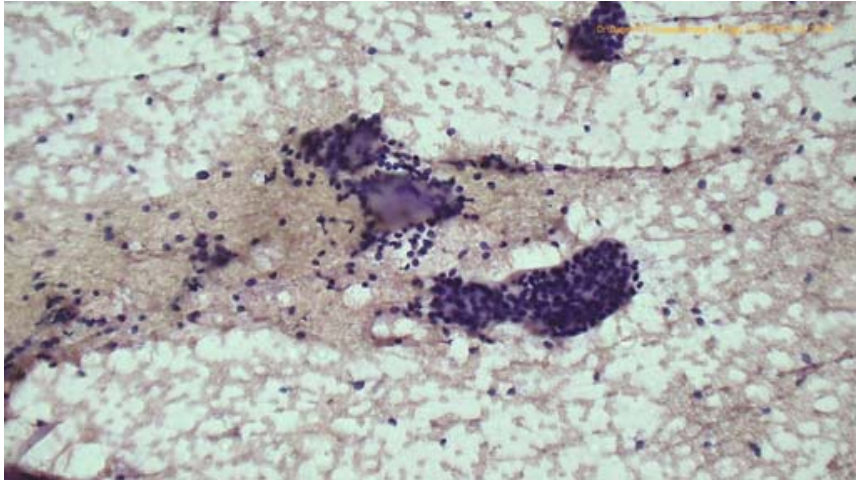

Figure 4. A FNA smear showed features of adenoid cystic carcinoma with typical acellular hyaline globules surrounded by malignant basaloid cells. The case correlated well with the histopathology (Papanicolaou stain x200).

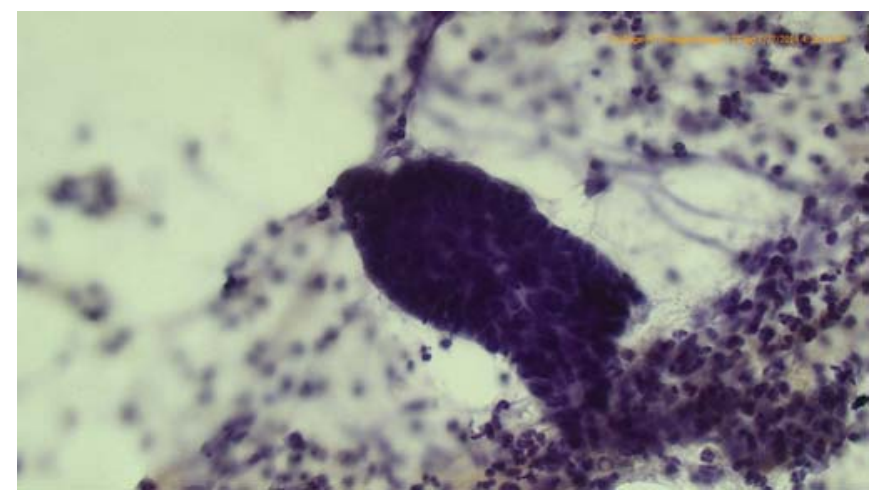

Figure 5. A FNA smear of basal cell carcinoma consists of tightly cohesive three-dimensional cluster of rounded and oval epithelial cells that are small with high nuclear cytoplasmic ratio, hyperchromatic nuclei and peripheral palisading in an inflammatory background (Papanicolaou stain x400).

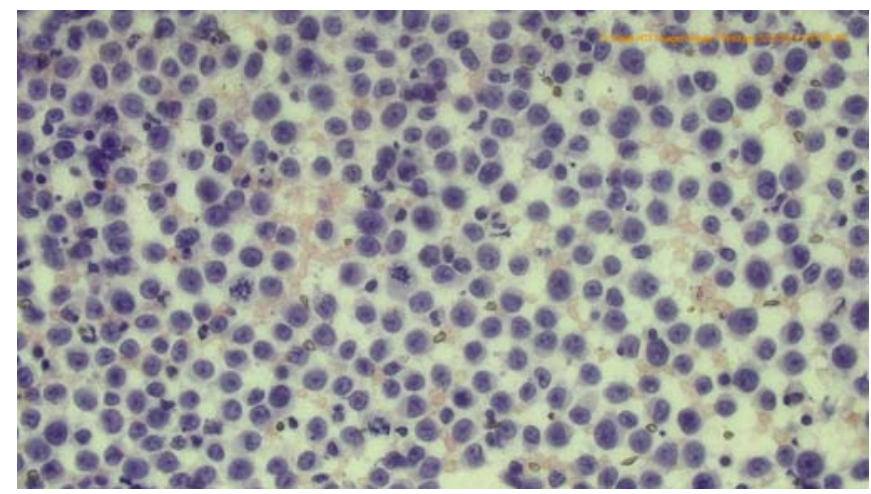

Figure 6. A FNA smear of malignant melanoma revealed loosely scattered malignant cells had rounded nuclei, high nucleo-cytoplasmic ratio, prominent nucleoli and frequent mitosis (Papanicolaou stain $\times 400$ ).

\section{Immunocytochemical results}

Three cases were provisionally diagnosed as "positive for undifferentiated malignant tumor cells not otherwise specified". The cases were subjected to panel of ICC markers on the cell block material. The cells of two cases were positive for cytokeratin protein confirming the diagnosis of undifferentiated carcinoma, the remaining case was positive for leukocyte common antigen (LCA) confirming the diagnosis of diffuse large cell lymphoma. One tonsillar mass was provisionally diagnosed as "atypical lymphoid 
proliferation", difficult to identify whether it is atypical reactive process or lymphoid neoplasm. The smears were subjected to ICC. The cells revealed light chain restriction and CD20 immunostain positivity, confirming the diagnosis of $B$ cell. The suspicious case for malignant melanoma was subjected to panel of ICC markers on the cell block material. The cells was positive for HMB-45 confirming the diagnosis of malignant amelanotic melanoma (Figure 7).

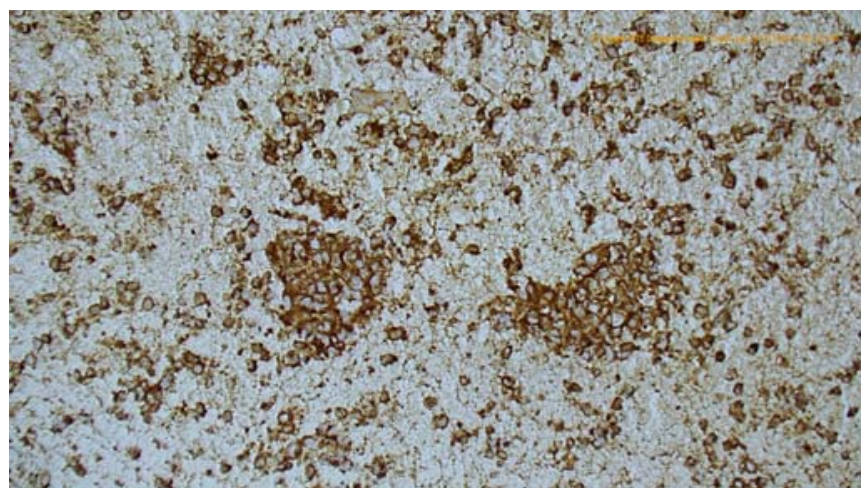

Figure 7. ICC stain for HMB-45 of the previous case cell block demonstrated diffuse cytoplasmic positivity of the malignant cells (Immunostain x200).

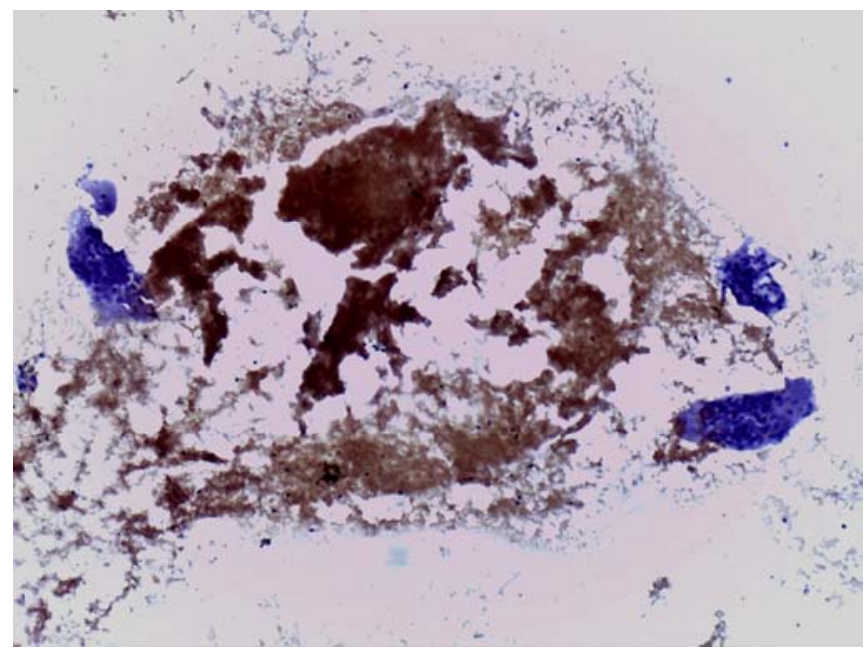

Figure 8. A FNA smear revealed multiple giant cells in hemorrhagic background with scattered inflammatory cells. The case was misdiagnosed cytologically as chronic granulomatous inflammation and diagnosed histopathologically as giant cell reparative granuloma (Papanicolaou stain $\times 100$ ).

Table 3. Comparative analysis of final cytological results and histopathological diagnoses

\begin{tabular}{|l|c|c|c|}
\hline \multirow{2}{*}{$\begin{array}{l}\text { Cytological } \\
\text { diagnoses }\end{array}$} & \multicolumn{2}{|c|}{ Histopathological diagnoses } & \multirow{2}{*}{ Total } \\
\cline { 2 - 3 } Benign & Benign & Malignant & 28 \\
\hline Malignant & $\begin{array}{c}25(89.3 \%) \\
\text { TN }\end{array}$ & $\begin{array}{c}3(10.7 \%) \\
\text { FN }\end{array}$ & 28 \\
\hline
\end{tabular}

TP, true positive cases; FN, false negative cases; FP, false positive cases; $T N$, true negative cases.
Table 4. Diagnostic reliability of cytological diagnoses

\begin{tabular}{|l|c|c|c|}
\hline \multirow{2}{*}{ Statistical parameters } & \multirow{2}{*}{ Value } & \multicolumn{2}{c|}{ 95\% CI (\%) } \\
\cline { 3 - 4 } & & Lower & Upper \\
\hline Sensitivity & 93.5 & 86.1 & 100 \\
\hline Specificity & 96.2 & 88.2 & 100 \\
\hline Positive predictive value (PPV) & 89.3 & 77.1 & 100 \\
\hline Negative predictive value (NPV) & 97.7 & 93.1 & 100 \\
\hline
\end{tabular}

$\mathrm{Cl}$, confidence interval.

Correlation of final FNAC results with clinico-pathological diagnoses

Histopathological diagnosis was available in all cases. Among the cytologically proven 28 benign cases, 25 cases were confirmed histopathologically as benign, while 3 cases were incorrectly interpreted cytologically as benign, resulting in a false negative rate of $6.5 \%$. On the other hand, of the 44 cytologically documented malignant cases, malignancy was histopathologically confirmed in all cases except one (Table 3), resulting in a false positive rate of $3.8 \%$.

In the current study, the diagnostic reliability was as follows: Sensitivity was $93.5 \%$; specificity $96.2 \%$; PPV 97.7\%; NPV $89.3 \%$ and overall diagnostic accuracy $94.4 \%$ (Table 4). A statistically significant relation was found between cytological and pathological diagnosis $(\mathrm{P}<0.001)$. Kappa was 0.882 indicating a good agreement between cytological and pathologic results.

On focusing on the detailed relation between cytological and pathological diagnoses, the diagnostic errors occurred in 4 cases: a case of polymorphous low grade adenocarcinoma (PLGA) that was reported as "pleomorphic adenoma", the patient was 45 year old female with a floor of the mouth mass $1.5 \times 1.5 \mathrm{~cm}$ for about one year with stationary course not responding to antibiotic therapy. The overlying mucosa showed erosions. FNAC was performed by extraoral approach. Review of the slides revealed high cellularity with epithelial cells formed sheets and clusters. The cells were uniform, with round to ovoid hyperchromatic nuclei and moderate cytoplasm. Myxoid matrix was dispersed in the background similar to that pleomorphic adenoma. The second case was well differentiated squamous cell carcinoma that was reported cytologically as "inflammatory lesion", the patient was 68 year old male complained of the pain and ulcerative lesion of the right middle tongue for about 6 months from which scrape cytology was performed. He was a smoker (one and half packet/day). He also had very low dental hygiene. Review of the slides showed mildly atypical squamous cells in a marked inflammatory background. The squamous cells showed a wide range of maturation ranging from small immature type to highly keratinized cells with the number of latter being predominant. The third case was follicular lymphoma that was reported as "reactive lymphoid hyperplasia", the patient was 58 years old male with a right tonsillar enlargement which was persisted for 1.5 months associated with dysphagia. The examination revealed tonsillar asymmetry, with the enlarged right tonsil, measuring about $2.0 \times 1.5 \mathrm{~cm}$. The tonsillar mucosal surface was erythematous. FNAC was performed. Review of the slides revealed mild to moderate cellularity of polymorphous lymphoid population with scattered histiocytes, the cytomorphology was favoring reactive lymph node. Therefore no ancillary techniques were requested. In the last case, a cytological diagnosis of squamous cell carcinoma was made but the histopathological examination proved to be chronic granulomatous inflammation. The patient was a 49 year old male with a $1.0 \times 1.5 \mathrm{~cm}$ mass in gingival mucosa for 4 months. FNAC was performed. On review, this case showed 
extensive necrotizing inflammation with dispersed mixed population of lymphocytes, plasma cells, epithelioid histiocytes and few discohesive clusters of atypical squamous cells with hyperchromatic nuclei misinterpreted as squamous cell carcinoma with liquifactive necrosis on cytology (Table 2).

Relation between types specific benign diagnoses with that of histopathology revealed that cytology was correctly identified 3 cases as benign but the exact typing was not accurately defined. Thus the rate of agreement in the diagnosis of benign tumors was $88 \%(22 / 25)$. Two cases were reported cytologically as chronic granulomatous inflammation but were diagnosed pathologically as giant cell reparative granuloma (Figure 8). Review of the slides revealed hypocellular hemorrhagic smears with multinucleated giant cells and scattered chronic inflammatory cells. One of these two cases revealed neutrophils in addition. Few fibrovascular fragments were also detected. Another case was cytologically diagnosed as myoepithelial tumor (Figure 2) but was proved pathologically to be pleomorphic adenoma with predominant myoepithelial component. The cellular smears composed plasmacytoid cells as well as fascicle and clusters of plump spindle shaped cells and few myxoid stroma. No glandular cells detected (Table 2).

Relation between type specific malignant diagnoses with that of histopathology revealed: in one patient, polymorphous low grade adenocarcinoma was misinterpreted by FNAC as adenoid cystic carcinoma, one cases of adenocarcinoma were cytologically diagnosed as mucoepidermoid carcinoma, 4 cases of mucoepidermoid carcinoma were cytologically diagnosed as undifferentiated carcinoma. Cytology was correctly identified these cases as malignant but the exact type was not correctly identified. For statistical analysis, these cases were considered as true positive (Table 2). The rate of agreement of histopathologic type in malignant tumors was $86 \%$ ( $37 / 43$ cases).

\section{Discussion}

The diagnosis of oral lesions can be made by a variety of diagnostic tools, including punch biopsy, open surgical biopsy, exfoliative cytology, and FNAC. Each tool has advantages and disadvantages. As compared to biopsy, FNAC is an outpatient procedure and has minimal risk of complications. When the material is adequate, it is possible to separate benign from malignant lesions as well as to subtype malignancies. By altering the direction of the needle inside the mass and by giving multiple passes, anyone can sample different parts of large tumors [4]. However, FNAC in intraoral lesions is reported to be less sensitive and specific than that of any other superficial lesions. This may be due to the small size, deep location of the lesions, limited space for maneuvering the needle and difficulty in fixing the intraoral lesion for adequate aspiration [5]. Although FNAC is used increasingly in the evaluation of lesions of the neck and head region, experience remains limited in the aspiration of intraoral masses [9]. The objective of this study was to find out the accuracy of FNAC procedure in the diagnosis of oral lesions by comparing the cytology of these tumors with their histopathological findings.

Reaching an accurate diagnosis of oral lesions permits applying specific surgical procedure. Management of oral cancer necessitates an aggressive surgery that might sacrifice adjacent structures. Using this management on benign lesions is not acceptable. It is, therefore, essential to accurately diagnose the lesions before undertaking any surgical procedure to choose the operation with little oral destruction [2].
In the current study a total of 72 patients underwent cytological and histopathological examination were later made to compare the cytological results. There was male predominance with ratio being 1.7:1.0. A similar result was achieved by Gupta et al., 2012 [5]. A closer to our results was recorded in the studies done by Daskalopoulou et al., 1997 [10] and Gillani et al., 2012 [1], where male to female ratio was 1.3:1.0 and 1.5:1.0, respectively. An obvious female predilection was reported by others with male: female ratio of 1:3 [4]. The incidence of oral lesions was equal in both sexes in another study [3].

Among the 72 cases, the age of patients ranged from 16 to 71 years with mean age of 43.9 years. The cause for this wide age distribution might be related to that there were variety of tumors which included in this study and they reported in different ages. In a study done by others, the age of patients ranged from 24 to 80 years with mean age of 51 years [1]. In another study, age of the patients ranged from 14 months to 84 years with a mean age of 46.9 [3]. The age range was 1-85 years with mean age was 39 years in the series of Isaac et al., 2013 [2].

Palate and tongue were the most frequently involved sites in the present study, in $29.2 \%$ and $26.4 \%$ respectively. These results were relatively comparable to $42 \%$ and $22.3 \%$ reported by others [5]. In another study, the most commonly involved sites were alveolar ridge $(27.5 \%)$ followed by palate $(25 \%)$, while the tongue involved in $12.5 \%$ of their cases [1]. In the study of Isaac et al., 2013 , tongue and palate were involved in $3.4 \%$ and $1.1 \%$ of their cases respectively [2].

In this series, sensitivity was $93.5 \%$; specificity was $96.2 \%$; positive predictive value (PPV) and negative predictive value (NPP) were $97.7 \%$ and $89.3 \%$ respectively. In a similar work, oral FNAC gave sensitivity and specificity of $93.75 \%$ and $95.45 \%$ respectively [11]. A near similar sensitivity and specificity were recorded with $96.7 \%$, and $98 \%$ results respectively [10]. In a study by Singh et al., 2011, the specificity and PPV were $100 \%$ but sensitivity was a bit low being $77.7 \%$ as there were six false negative cases [8]. In another study, overall sensitivity was $100 \%$ and specificity $89 \%$ [1]. PPV was calculated to be $97 \%$ and NPV $100 \%$. In 2008, Dr. Singh and his colleagues found out that sensitivity was $97.8 \%$, and specificity $88.35 \%$ with PPV $93.93 \%$ and NPV $93.75 \%$ [3].

The accuracy rate achieved in the current work was $94.4 \%$. Accuracy rates as high as $97.5 \%$ had been reported by others [1, 10, 12]. Saleh et al., 2008 [4] and Gupta et al., 2012 [5] were concluded low accuracy rate of $87.7 \%$ and $86.6 \%$, respectively. The diagnostic accuracy of oral cytopathology is variable which obviously depends on a number of factors such as the experience of the cytologists, inherited limitations of lesions, the type and quality of sample material and regions where FNAC is used as a common practice and areas where it is not [1].

The most commonly aspirated malignant tumor in the current study was squamous cell carcinoma constituting $52.3 \%$ (23/44) of all malignancy. This finding is explainable as squamous cell carcinoma accounts for the vast majority of malignancies of head and neck region [9]. Gillani et al., 2012 [1] and Isaac et al., 2013 [2] also encountered maximum of squamous cell carcinoma in their studies, $75 \%$ and $73.3 \%$ respectively. In the current study, $95.7 \%$ (22/23) of squamous cell carcinoma cases were accurately diagnosed on FNAC. In studies performed by others, $100 \%$ of their squamous cell carcinoma cases were correctly diagnosed cytologically $[1,2]$. In the study on oral squamous cell carcinoma, it was found that FNAC was true positive in $92.9 \%$; hence it was concluded that FNAC can be safely used as reliable diagnostic test 
for picking up squamous cell carcinoma of oral cavity [13]. In the present study, only one false positive squamous cell carcinoma was reported. This case emphasizes that a diagnosis of squamous cell carcinoma in the presence of inflammation should be offered with extreme caution due to the reactive squamous atypia [13]. The attention to scattered atypical squamous cells with hyperchromatic irregular wrinkled nuclei and considering the presence of a mass lesion may have been good clues to suspect squamous cell carcinoma in oral cavity in setting of inflammatory background [4].

The most commonly aspirated benign lesion in the current study was inflammation constituting $42.9 \%$ of all benign diagnoses $(12 / 28)$. One case that showed inflammatory diagnosis on cytology was found to be well differentiated squamous cell carcinoma on histopathology (false negative cases). Misdiagnosis of well differentiated squamous cell carcinoma as a benign lesion or an acute inflammation commonly occurs in clinical practice, thus if clinical index of suspicion is high, even in the presence of numerous inflammatory cells, a benign diagnosis should never be rendered [14]. The main treatment of oral squamous cell carcinoma is complete surgical excision. Lymph node dissection is performed when lymphadenopathy is evident. Radiation therapy is often used as an adjunct to surgery. Chemotherapy is reserved for palliative therapy [13].

Other commonly aspirated tumors were of minor salivary gland tumors. There were 18 cases in total. Nine cases were correctly matched with the pathology report. One case was false negative. Eight cases were correctly identified as being benign or malignant on cytology but the exact type was not correctly determined on correlation with histopathology; in one case, pleomorphic adenoma with predominant myoepithelial cells was interpreted cytologically as myoepithelial tumor. Others reported that cytological diagnosis of pleomorphic adenoma in most instances is straightforward. Problem in the diagnosis, however, can be encountered if there is a predominance of one of its elements. If the epithelial or myoepithelial cells predominate, myoepithelioma or basal cell adenoma may be suspected. The fine needle may not aspirate the scant component, therefore presenting diagnostic difficulties [15]. However, their separation does not seem very important since their treatment is the same [16]. One case of adenocarcinoma was cytologically diagnosed as mucoepidermoid carcinoma and 4 mucoepidermoid carcinoma cases were diagnosed cytologically as undifferentiated carcinoma. It is well-known that the morphological variability of mucoepidermoid carcinoma of the salivary glands may lead to interpretative difficulties on FNAC diagnosis [16]. High grade neoplasms are more easily recognizable as malignant with or without exact typing and, therefore, the appropriate management is complete and aggressive resection [17]. One patient of polymorphous low grade adenocarcinoma (PLGA) was misinterpreted by FNAC as adenoid cystic carcinoma. Although adenoid cystic carcinoma is a high grade tumor with high capacity for invasion and metastasis, in most cases, it does not show cell atypia or mitotic figures and can be misinterpret with other benign or low grade tumor. In some cases, differentiation from PLGA is not possible. Considering the difference in treatment planning and prognosis between these tumors, more effort must be done for such differentiation [18]. PLGA is slowly growing tumor. Its treatment is wide surgical excision as metastasis to cervical lymph nodes is not common and distant metastasis is rare. If the lesion recurs it can be successfully treated by another surgical excision.
Treatment of adenoid cystic carcinoma is aggressive surgical resection [5]. The last false negative minor salivary gland case which was given pleomorphic adenoma on cytology was found to be PLGA on histopathology. The highly cellular smear with uniform bland epithelial cells and dispersed myxoid matrix in the background led to the mis-diagnosis. A similar false negative case was reported by others $[19,8,5]$. PLGA may be difficult to diagnose cytologically as its features overlap considerably with those of other tumors as well as the experience with cytological findings in these tumors is limited [5].

Oral lymphoma was recorded in 5 cases. One case was provisionally diagnosed as "positive for undifferentiated malignant tumor cells not otherwise specified". Another one was provisionally diagnosed as "atypical lymphoid proliferation", difficult to identify whether it is atypical reactive process or lymphoid neoplasm. These two cases were subjected to ICC markers confirming the diagnosis of B cell lymphoma. These results were in concordance with that reported by others who concluded that, fine needle aspiration (FNA) in conjunction with ICC is superior for the diagnosis of non-Hodgkin's lymphoma of the oral cavity [20]. Gunjan et al., 2011 in his study on extra-nodal oral lymphomas concluded that FNAC shows infiltration of polymorphonuclear cells, plasma cells and lymphocytes hence giving inconclusive appearance [21]. In the present study, one tonsillar reactive lymphoid hyperplasia case was proved to be follicular lymphoma, centrocytic/centroblastic on histopathology (false negative case). Review of the slides revealed mild to moderate polymorphous cellularity that still favoring reactive lymph node. Gupta et al., 2012 in their series reported 2 falsenegative lymphoma cases due to sampling error from the posterior soft palate highlighting the difficulties in approaching deep intraoral sites [5]. This problem might be responsible for our false negative case. It is reported that unilateral tonsillar enlargement is considered to be a sign of a potential tonsillar malignancy when other causes of the unilateral tonsillar enlargement, such as acute infection, have been excluded. This sign was recorded in $84 \%$ of tonsillar lymphoma cases in a previous study [22].

The current work showed an accuracy of $97.7 \%(43 / 44)$ for the diagnosis of malignant tumors. An accuracy of $100 \%$ for malignancy was reported by others [2, 4]. A lower accuracy rate of $94 \%$ for malignancy was reported by Gandhi et al., 2011. The current work showed an accuracy of $89.3 \%$ (25/28) for the diagnosis of benign tumors. In another studies, intraoral FNAC gave a diagnostic accuracy of $90 \%$ and $92 \%$ respectively for benign lesions [2, 11]. An accuracy of $100 \%$ for benign lesions was reported by others [1].

\section{Conclusion}

Cytological examination of oral cavity is an accurate and reliable diagnostic tool in the pre-operative work up of patients with intraoral lesions. Detailed cytomorphologic examination coupled with clinical data and appropriate immunocytochemical study, in some cases, can lead to an accurate diagnosis. Although most cases are not problematic, there are few cases that can be challenging to the cytopathologists especially minor salivary gland masses. These pifalls, therefore, should always be kept in mind when faced with a difficult and challenging case of oral cavity.

Conflict of interest: none declared. 


\section{References}

1. Gillani M, Akhtar F, Ali Z, Naz I, Atique M, Khadim MT. Diagnostic accuracy, sensitivity, specificity and positive predictive value of fine needle aspiration cytology (FNAC) in intra oral tumors. Asian Pacific $J$ Cancer Prev 2012; 13: 3611-3615. (PMID: 23098442)

2. Isaac $U$, Isaac JS, Isaac AD. Fine needle aspiration cytology of oral lesions. J Pak Oral \& Dent 2013; 33(2): 266-270.

3. Singh D, Sinha BK, Shyami G, Baskota D K, Guragain RPS, Adhikari P. Efficacy of fine needle aspiration cytology in the diagnosis of oral and oropharyngeal tumors. Intl Arch Otorhinolaryngol 2008; 12(1): 99-104.

4. Saleh HA, Clayman L, Masri H. Fine needle aspiration biopsy of intraoral and oropharyngeal mass lesions. Cytojournal 2008; 5: 4. (doi: 10.1186/1742-6413-5-4) (PMID: 18373853)

5. Gupta N, Banik T, Rajwanshi A, Radotra BD, Panda N, Dey P, Srinivasan R, Nijhawan R. Fine needle aspiration cytology of oral and oropharyngeal lesions with an emphasis on the diagnostic utility and pitfalls. J Can Res Ther 2012; 8(4): 626-629. (PMID: 23361285) (doi: 10.4103/0973-1482.106581)

6. Santos AP, Sugaya NN, Pinto Junior Ddos S, Lemos Junior CA. Fine needle aspiration biopsy in the oral cavity and head and neck region. Braz Oral Res 2011; 25(2): 186-191. (PMID: 21537646) (doi: 10.1590/S1806-83242011000200015)

7. Abdullah $\mathrm{BH}$, Majeed $\mathrm{AH}, \mathrm{Al}-\mathrm{Rawy}$ k, Al-Ani FH. The value of cytobrush technique in the diagnosis of oral ulcerative lesions. Med J Babylon 2009; 6(3): 484-493.

8. Singh S, Garg N, Gupta S, Marwah N, Kalra R, Singh V, Sen R. Fine needle aspiration cytology in lesions of oral and maxillofacial regions: Diagnostic pitfalls. J Cytol 2011; 28(3): 93-97. (doi: 10.4103/09709371.83461) (PMID: 21897540)

9. Lehri IA, Shah MA, Baloch MR, Tariq M. Diagnosis of oral squamous cell carcinoma on fine needle aspiration cytology. J Pak Dent Assoc 2004; 13(13): 148-150.

10. Daskalopoulou D, Rapidis AD, Maounis N, Markidou S. Fine-needle aspiration cytology in tumors and tumor-like conditions of the oral and maxillofacial region. Cancer 1997; 81(4): 238-252. (PMID: 9292739)

11. Gandhi S, Lata J, Gandhi N. Fine needle aspiration cytology: A diagnostic aid for oral lesions. J Oral Maxillofac Surg 2011; 69(6): 16681677. (doi: 10.1016/j.joms.2010.06.188) (PMID: 21216072)

12. Deng FM, Hsu J, Khurana KK. Transmucosal fine needle aspiration of oral and pharyngeal lesions. ISRN Pathology 2011: 267145. (doi: 10.5402/2011/267145)

13. Seetharam S, Ramachandran C. Fine needle aspiration cytology as a diagnostic test for oral squamous cell carcinoma. Oral Dis 1998; 4: 180186. (PMID: 9972168)

14. Scheifele C, Schmidt-Westhausen AM, Dietrich T, Reichart A. The sensitivity and specificity of the OralCDx technique: evaluation of 103 cases. Oral Oncol 2004; 40: 824-828. (PMID: 15288838) (doi: 10.1016/j.oraloncology.2004.02.004)

15. Elsheikh TM, Bernacki EG. Fine needle aspiration cytology of cellular pleomorphic adenoma. Acta Cytol 1996; 40(6): 1165-1175. (PMID: 8960024)

16. Ul-Aan N, Tanwani AK. Pitfalls in salivary gland fine-needle aspiration cytology. Int J of Pathol 2009; 7(2): 61-65.

17. Wade VT, LiVolsi VA, Montone KT, Baloch ZW. A cytohistologic correlation of mucoepidermoid carcinoma: Emphasizing the rare oncocytic variant. Patho Res Int 2011: 135796. (PMID: 21437180) (doi: 10.4061/2011/135796)

18. Saghravanian N, Mohtasham N, Jafarzadeh H. Comparison of immunohistochemical markers between adenoid cystic carcinoma and polymorphous low-grade adenocarcinoma. J Oral Sci 2009; 51(4): 509514. (PMID: 20032601) (doi: 10.2334/josnusd.51.509)

19. Gibbons D, Saboorian MH, Vuitch F, Gokaslan ST, Ashfaq R. Fine needle aspiration findings in patients with polymorphous low grade adenocarcinoma of the salivary glands. Cancer Cytol 1999; 87: 31-36. (PMID: 10096357)
20. Liliemark J, Tani E, Mellstedt H, Skoog L. Fine-needle aspiration cytology and immunocytochemistry of malignant non-Hodgkin's lymphoma in the oral cavity. Oral surg Oral med Oral pathol 1989; 68: 599-603. (PMID: 2812714) (doi: 10.1016/0030-4220(89)90247-8)

21. Shah GH, Panwar SK, Chaturvedi PP, Kane SN. Isolated primary extranodal lymphoma of the oral cavity: A series of 15 cases and review of literature from a tertiary care cancer centre in India. Indian J Med Pediatr Oncol 2011; 32: 76-81. (doi: 10.4103/0971-5851.89776) (PMID: 22174494)

22. Murthy S, Panduranga C. Fine needle aspiration diagnosis of extranodal non-Hodgkin's lymphoma of the tongue. J Cytol 2011; 28(2): 81-83. (doi: 10.4103/0970-9371.80750) (PMID: 21713153)

\section{Authors:}

Nesreen Hassan Hafez - MD, PhD, Lecturer, Cytology unit, Pathology Department, National cancer Institute, Cairo University, Giza, Egypt; Mohamed Ibrahim Fahim - MB, BCh, Assisstent lecturer, Surgical Oncology Department, National cancer Institute, Cairo University, Giza, Egypt. 